\title{
Fear of falling and cognitive impairment in elderly with different social support levels: findings from a community survey in Central Vietnam
}

Thi Hue Man Vo ${ }^{1}$, Keiko Nakamura ${ }^{1 *}$, Kaoruko Seino ${ }^{1}$, Hoang Thuy Linh Nguyen ${ }^{1,2,3}$ and Thang Van Vo ${ }^{2,3}$

\begin{abstract}
Background: Fear of falling (FoF) in the elderly is one of the major public health concerns in this era of aging of the population. As there is limited evidence on how cognitive function may differ by social support level in relation to FoF among the elderly, this cross-sectional study aims to investigate the prevalence of FoF and the associations between cognitive impairment and FoF by the social support level, after adjustments for potential confounders.

Methods: Data from the "Health needs assessment of elderly in Thua Thien Hue Province, Vietnam in 2018" survey of 725 elderly aged 60 years or older were used for analysis. FoF was assessed using the Fall Efficacy ScaleInternational. High FoF was defined as a score above 28. The Multidimensional Scale of Perceived Social Support was used to measure the perception of support. Logistic regression analysis was performed to investigate the association between cognitive function and FoF by social support levels $(p<0.05)$.

Results: The prevalence of high FoF among the elderly was 40.8\%. Female gender, advanced age, a marital status of single or formerly married, living alone, history of injury, history of falls, chronic diseases (arthritis and/or hypertension), limitations of the IADL and BADL, visual difficulty and walking difficulty, low social support, and cognitive impairment were all significantly associated with a high FoF. After adjustments for the age, gender, marital status, history of falls and health-related factors, cognitive impairment remained significantly associated with a high FoF among the elderly with a low to moderate social support level $(\mathrm{OR}=2.97,95 \% \mathrm{Cl} 1.49-5.89)$, but not in those with a high social support level.

Conclusions: A high FoF was associated with impairment of cognitive function among the elderly who perceived themselves as having low or moderate support levels, even after adjustments for socio demographic and physical functional factors. However, this association was not observed among the elderly who perceived themselves as having high social support levels. Fall prevention programs for the elderly with various levels of social support should be carefully devised, keeping in mind the cognitive function levels of the target recipients.
\end{abstract}

Keywords: Fear of falling, Cognitive impairment, Social support, Elderly

\footnotetext{
* Correspondence: nakamura.ith@tmd.ac.jp

'Department of Global Health Entrepreneurship, Division of Public Health,

Graduate School of Medical and Dental Sciences, Tokyo Medical and Dental University, Yushima 1-5-45, Bunkyo-ku, Tokyo 113-8519, Japan

Full list of author information is available at the end of the article
}

(C) The Author(s). 2020 Open Access This article is licensed under a Creative Commons Attribution 4.0 International License, which permits use, sharing, adaptation, distribution and reproduction in any medium or format, as long as you give appropriate credit to the original author(s) and the source, provide a link to the Creative Commons licence, and indicate if changes were made. The images or other third party material in this article are included in the article's Creative Commons. licence, unless indicated otherwise in a credit line to the material. If material is not included in the article's Creative Commons licence and your intended use is not permitted by statutory regulation or exceeds the permitted use, you will need to obtain permission directly from the copyright holder. To view a copy of this licence, visit http://creativecommons.org/licenses/by/4.0/ The Creative Commons Public Domain Dedication waiver (http://creativecommons.org/publicdomain/zero/1.0/) applies to the data made available in this article, unless otherwise stated in a credit line to the data. 


\section{Background}

Globally, falls account for $40 \%$ of all deaths from injuries, and affect one-third of the elderly population each year [1]. Fatal falls rates are highest among adults over the age of 60 years [1].

Considering the implications of falls in older persons, fear related to falls should also not be neglected. Fear of falling (FoF), defined as a lasting concern about falling that leads to avoidance of daily activities [2], is also a highly prevalent problem [3]. FoF increases with age and is associated with adverse consequences among the elderly, including a poor quality of life [4], mental and functional decline [4-8], a lower level of satisfaction with life [9], and restricted social interactions [7, 10]. As falls and FoF are closely linked with each other by shared predictors, each is a risk factor for the other, and FoF was reported to be an independent predictor of falls [11], recent research has been focused on investigating the determinants of FoF, in an effort to prevent both FoF and falls in the community-dwelling elderly.

A number of studies have already been published on the FoF and its risk factors in the elderly. Although cognitive impairment has frequently been mentioned a factor that is significantly associated with the FoF, reports on the relationship between cognitive impairment and FoF are conflicting. In some previous studies, impaired cognition was identified as a predictor of FoF $[4,5,12]$, while in others, no association between cognitive impairment and FoF was observed [13]. In addition, the proportion of Vietnamese elderly who had cognitive symptoms of dementia was recently reported to be high at $46.4 \%$ [14]. As there have been limited large-scale population studies investigating FoF as well as the relationship between FoF and cognitive impairment in Vietnam, it is crucial to obtain a clearer understanding about this association in a large communitybased sample.

Social support is well-known to play a vital role in maintaining well-being in old age [15], however, few studies have investigated the difference in the relationship between cognitive function and FoF according to the level of social support available to the elderly. Since higher cognitive function is known to be associated with a higher level of social support [16], and good social support is known to be associated with a lower odds of the FoF [17-19], the level of social support available may have influence on the association between cognitive impairment and FoF.

In developing countries where the population is rapidly ageing, fall-related issues have yet to receive adequate attention. Vietnam is among the countries with fastest rates of ageing in Asia [20] and it is predicted that the proportion of persons aged 60 years old or older will reach $20 \%$ of the total population by the year 2038 [21]. A community survey in 2015 showed that the prevalence of high FoF (FES-I scores ranged from 28 to 64) among
Vietnamese elderly was high, at 64\% [6]. Although the risk factors of FoF have been widely explored, there are many aspects of FoF that still remain to be investigated further, and how factors influencing the FoF might have different levels of influence depending on the social support available to the elderly remains unknown in the context of Vietnam.

Thus, this study was performed to investigate the prevalence of FoF and the differential associations between cognitive impairment and FoF depending on the social support level in a community of elderly in Vietnam.

\section{Methods \\ Study area}

The study was performed in Thua Thien Hue Province, Central Vietnam. The province comprises 9 districts and 152 communes with a total population of 1.154 million people as of a census conducted in 2017 [22].

\section{Sample size and sampling method}

In Vietnam, people aged 60 years and over are considered elderly [23]. Sample size needed was calculated as 726 by the standard formula for cross-sectional studies with a $95 \%$ confidence level, a 5\% margin of error, a design coefficient of 2 and $p=0.38$ based on an estimation of the proportion of the elderly who had at least one difficulty in daily life activities from the previous study [24]. According to this calculation, 730 participants from Hue city and Phu Vang district were recruited by a twostage random cluster sampling method. In the first stage, two quarters among the 27 quarters of Hue city (urban area) and three communes out of 20 communes in Phu Vang district (rural area) were randomly selected. In the second, in each of the selected quarters and communes, 146 households with people aged 60 years old or over were randomly selected based on a list of households held in the commune health centers.

\section{Data collection}

A cross-sectional study was conducted in the elderly individuals living in their own households in Thua Thien Hue Province between June and July 2018. Face to face interview using a structured questionnaire was performed to collect data from the selected households. We excluded participants who refused to take part in the survey or were unable to speak. Data of a total of 725 participants were finally included in the analysis, representing a response rate of $99 \%(725 / 730)$.

\section{Survey instruments}

The data collection instrument was adapted from a reference questionnaire developed by a research team from the Tokyo Medical and Dental University, and containing questions pertaining to the socio-demographic 
characteristics, physical functional status, FoF, perceived social support and cognitive function of the participants. The instrument was translated from English into Vietnamese and then translated back to English by two Vietnamese researchers to check for the accuracy of the translation. The Vietnamese questionnaire was pilottested with 20 elderly living in community in Thua Thien Hue province. A few modifications in wording in questions were made to improve comprehensibility and to ensure the cultural relevance in Vietnam.

\section{Ethical consideration}

Ethical approval was obtained from the Institutional Ethics Committee of Hue University of Medicine and Pharmacy (Ethics Approval No. H2018/148 dated 12 May 2018). Written informed consent was obtained from each of the participants or from their guardian prior to the interviews. Study ID numbers were assigned to all the participants to protect their confidentiality.

\section{Study variables \\ Fear of falling}

FoF was assessed using the Falls Efficacy ScaleInternational (FES-I), which contains 16 items. The overall scores can range from 16 to 64, with higher scores indicating a higher FoF. Scores of 16-19 represent low levels of concern; scores of 20-27 represent moderate levels of concern, and scores of 28-64 represent high levels of concern. Good validity and reliability of FES-I have been demonstrated in a previous study [25].

\section{Perceived social support}

Perceived social support was measured by The Multidimensional Scale of Perceived Social Support (MSPSS), to assess the participants' perception of support from three sources: family, friends and significant other. The scale is comprised of 12 items, with 4 items for each category scored on a seven-point Likert scale ranging from 'very strongly disagree' to 'very strongly agree'. The total scores range from 12 to 84 . Mean total scores in the range of 1.0 to 2.9 represent low levels of support, scores of 3.0 to 5.0 represent moderate levels of support, and scores of 5.1 to 7.0 represent high levels of support [26]. The good validity, high internal consistency and reliability of MSPSS has been shown in a previous study [26].

\section{Cognitive function}

The Mini-Mental State Examination (MMSE) was used to evaluate the cognitive function. Cognitive impairment was defined as a score lower than the cutoff point of 23, which is the most commonly used cutoff score to detect cognitive impairment [27].

\section{Functional limitation}

Performance in the activities of daily living was assessed by the Barthel ADL index and Lawton Instrumental Activities of Daily Living Scale (IADL), as follows:

- The IADL scale measured eight domains of function: use of telephone, shopping, food preparation, housekeeping, laundry, mode of transportation, medication, and managing finance with the possible summary score ranging from 0 (low function) to 8 (high function).

- The Barthel ADL scale pertained to 10 items: feeding, bathing, grooming, dressing, bowels, bladder, toilet use, transfers, mobility, and use of stairs. Response categories were scored based on each item and total possible score ranges from 0 to 20 .

Higher total scores in both scales indicate a greater level of independence. Total independence was categorized as 'no limitation', and partial dependence and complete dependence were categorized as 'limitation' [28, 29].

\section{Socio-demographic characteristics and physical functional status}

The questionnaire consisted of a variety of sociodemographic characteristics, including the age, gender, residential area, education level, marital status and living arrangement. Physical functional status variables included experience of injury, chronic diseases (arthritis, hypertension and others), functional limitation status, visual ability and walking ability.

\section{Data analysis}

Data were summarized using descriptive analysis and differences in the levels of FoF by the participants' sociodemographic, physical functional status and cognitive function characteristics. Physical functional status included experience of injury, history of falls, arthritis, hypertension, limitation of IADL and BADL, visual ability and walking ability. A Chi-square test was used to assess the association between the three groups of FoF and above mentioned parameters. As scores were not normally distributed, the overall FES-I score was categorized. For the analysis with logistic regression model, the dependent variable "Fear of falling" was categorized as "high FoF" and "not high FoF" (combining the "Low FoF" and "Moderate FoF" groups). The associations between the independent variables and the dependent variable "Fear of falling" were investigated by bivariate analysis. Multivariate logistic regression analysis was used to examine the association between cognitive impairment and FoF, after adjustments for sociodemographic factors and the physical functional status, by adjusted odd ratios with $95 \%$ confidence intervals. 
Data analysis was performed using SPSS version 22. $P$ values of less than 0.05 were considered as indicative of statistical significance.

\section{Results}

The characteristics of participants by three levels of FoF were shown in Table 1. The total sample size was 725 elderly persons aged 60 or over, of whom 423 were females. The prevalence of history of fall, hypertension, arthritis, diabetes and stroke were 7.4, 43.9, 33.5, 10.5 and $4 \%$, respectively. The prevalence of elderly with a high FoF was $40.8 \%$. The overall prevalence of a high FoF was greater among the cognitive-impaired elderly than among those with normal cognition (76.4 and $33.6 \%, p<0.001)$.

Table 2 showed the results of bivariate analysis, which revealed the existence of an association between the participants' characteristics and the degree of FoF. Factors that were significantly associated with a high FOF among all subjects included: female gender, age 80 years or over, marital status of being single or formerly married, living alone, and a low social support level $(p<$ $0.05)$. A positive history of fall was associated with a higher likelihood of high FoF among the elderly (OR: 5.75, 95\% CI: 2.97-11.12). Physical functional status variables, including experience of injury in the last 12 months, presence of arthritis and hypertension; limitations of IADL and BADL; visual and walking ability showed significant association with a high FoF $(p<0.01)$.

As shown in Table 3, after adjustments for socio demographic factors and the physical functional status, elderly with impaired cognition had an approximately 3 times higher likelihood of having a high FoF as compared to those without cognitive impairment among those with low and moderate perceived levels of social support (AOR: 2.97, 95\% CI: 1.49-5.89). In contrast, in the group with a high perceived social support level, cognitive impairment was not significantly associated with a high FoF. Female participants with low and moderate perceived levels of social support were 1.9 times more likely to have a high FoF as compared to males of the same group (AOR: 1.99, 95\% CI: 1.10-3.59). History of fall, limitation of the IADL, limitation of the BADL and difficulty in walking were statistically significant associated with a high FoF in the entire sample.

\section{Discussion}

The results of the current study showed that $40.8 \%$ of the participants had a high FoF. The factors associated with a high FoF varied with the perceived level of social support. Among the participants with perceived low and moderate levels of social support, cognitive impairment was associated with a high FoF, whereas in the participants with a high perceived level of social support, this relationship of the FoF with cognitive function was not observed.

\section{Prevalence of high FoF}

This study conducted in a population-representative sample of 725 Vietnamese elderly living in rural and urban areas revealed a high prevalence of FoF. Overall, $40.8 \%$ of the elderly were identified as having a high FoF. This considerably high prevalence as compared to previous reports $[9,30,31]$ might need to be interpreted from the perspective of the study location [18, 32], age of the participants (mean age: $72 \pm$ 8.8) and standardized measurement of the FoF [3]. While safe environment could have effects on the FoF $[18,32]$, another possible reason is Thua Thien Hue's long rainy season, which normally lasts for 4 months, from September to December, with a large amount of rainfall [33], which leaves surfaces slippery and unsafe for the elderly to perform their daily activities. This finding suggests the high level of concern for falls among Vietnamese elderly living in the community. Therefore, attention should be paid to this population in terms of falls and fall-related issues.

\section{Cognitive impairment and FoF among different perceived social support levels}

The univariate analyses in the present study indicated that elderly persons with impaired cognition had a higher odd of experiencing a high FoF. With advancing age, attention and memory are the two aspects of cognition that are the most severely affected [34]. Impairment of cognitive function in the elderly, characterized by a poorer performance in memory, executive functions, attention and information processing, has been reported as a predictor of the onset of FoF [5] and to also be associated with higher levels of anxiety [35], which, in turn, was shown to be associated with a FoF [36]. Furthermore, in the logistic regression model with adjustments for confounding factors performed to determine the association between the participant's characteristics and the likelihood of a high FoF (Additional file 1), elderly with cognitive impairment were approximately 2 times more likely to have a high FoF than those with normal cognition. This finding confirmed the effect of cognitive impairment on the high FoF among the study participants.

An even stronger association between cognition and FoF was observed among the elderly with low and moderate perceived levels of social support in the fully adjusted model: elderly with cognitive impairment in this group had a nearly 3 times higher likelihood of having high a FoF. This result can be explained by the observed characteristics of the study participants with two different perceived levels of social support, as well as by the two-way relationship between the perceived social 
Table 1 Baseline characteristics of the participants according to fear of falling status

\begin{tabular}{|c|c|c|c|c|c|c|}
\hline \multirow[t]{2}{*}{ Characteristics of participant } & & \multirow[t]{2}{*}{$\begin{array}{l}\text { All } \\
(n=725)\end{array}$} & \multirow{2}{*}{$\begin{array}{l}\text { Low FoF } \\
(n=272) \\
\%\end{array}$} & \multirow{2}{*}{$\begin{array}{l}\text { Moderate FoF } \\
(n=157) \\
\%\end{array}$} & \multirow{2}{*}{$\begin{array}{l}\text { High FoF } \\
(n=296) \\
\%\end{array}$} & \multirow[t]{2}{*}{$P$ value $^{1}$} \\
\hline & & & & & & \\
\hline \multicolumn{7}{|c|}{ Socio-demographic characteristic } \\
\hline \multirow[t]{2}{*}{ Gender } & Female & 423 & 28.1 & 20.8 & 51.1 & $<0.001$ \\
\hline & Male & 302 & 50.7 & 22.8 & 26.5 & \\
\hline \multirow[t]{3}{*}{ Age (yr) } & $60-69$ & 340 & 51.2 & 21.5 & 27.4 & $<0.001$ \\
\hline & $70-79$ & 209 & 30.6 & 25.8 & 43.5 & \\
\hline & $\geq 80$ & 176 & 39.3 & 17.0 & 63.6 & \\
\hline \multirow[t]{2}{*}{ Residential area } & Hue City & 443 & 38.8 & 23.0 & 38.1 & 0.173 \\
\hline & Phu Vang District & 282 & 35.5 & 19.5 & 45.0 & \\
\hline \multirow[t]{3}{*}{ Marital status } & Married & 524 & 42.4 & 22.5 & 35.1 & $<0.001$ \\
\hline & Single or formerly & 201 & 24.9 & 19.4 & 55.7 & \\
\hline & married & & & & & \\
\hline \multirow[t]{3}{*}{ Education level } & Low education & 195 & 22.6 & 16.4 & 61.0 & $<0.001$ \\
\hline & Primary to high school & 468 & 42.3 & 23.3 & 34.4 & \\
\hline & College and higher & 55 & 52.7 & 25.5 & 21.8 & \\
\hline \multirow[t]{2}{*}{ Living arrangement } & Alone & 65 & 24.6 & 15.4 & 60.0 & 0.004 \\
\hline & Living with others & 660 & 38.8 & 22.3 & 38.9 & \\
\hline \multicolumn{7}{|l|}{ Physical functional status } \\
\hline \multirow[t]{2}{*}{ Experience of injury } & No & 665 & 39.7 & 22.6 & 37.7 & $<0.001$ \\
\hline & Yes & 60 & 13.3 & 11.7 & 75.0 & \\
\hline \multirow[t]{2}{*}{ History of fall } & Yes & 54 & 14.8 & 7.4 & 77.8 & $<0.001$ \\
\hline & No & 671 & 39.3 & 22.8 & 37.9 & \\
\hline \multirow[t]{2}{*}{ Hypertension } & Yes & 318 & 32.7 & 21.1 & 46.2 & 0.022 \\
\hline & No & 407 & 41.3 & 22.1 & 36.6 & \\
\hline \multirow[t]{2}{*}{ Arthritis } & Yes & 243 & 30.9 & 18.9 & 50.2 & 0.001 \\
\hline & No & 482 & 40.9 & 23.0 & 36.1 & \\
\hline \multirow[t]{2}{*}{ Limitation of the IADL } & No & 484 & 50.6 & 24.8 & 24.6 & $<0.001$ \\
\hline & Yes & 241 & 11.2 & 15.4 & 73.4 & \\
\hline \multirow[t]{2}{*}{ Limitation of the BADL } & No & 598 & 43.5 & 24.7 & 31.8 & $<0.001$ \\
\hline & Yes & 127 & 9.4 & 7.1 & 83.5 & \\
\hline \multirow[t]{2}{*}{ Visual ability } & No difficulty & 370 & 50.3 & 21.9 & 27.8 & $<0.001$ \\
\hline & Have difficulty & 355 & 24.2 & 21.4 & 54.4 & \\
\hline \multirow[t]{2}{*}{ Walking ability } & No difficulty & 503 & 48.3 & 26.6 & 25.0 & $<0.001$ \\
\hline & Have difficulty & 222 & 13.1 & 10.4 & 76.6 & \\
\hline \multirow[t]{3}{*}{ Social support } & Low & 71 & 25.4 & 16.9 & 57.7 & 0.002 \\
\hline & Moderate & 352 & 35.8 & 26.1 & 38.1 & \\
\hline & High & 302 & 42.4 & 17.5 & 40.1 & \\
\hline \multirow[t]{2}{*}{ Cognitive function } & Normal & 602 & 43.2 & 23.3 & 33.6 & $<0.001$ \\
\hline & Impairment & 123 & 9.8 & 13.8 & 76.4 & \\
\hline
\end{tabular}

${ }^{1} \mathrm{P}$-value of Chi-square test for the three group of FoF and characteristics of participants

support level and the fear of falling. A lower perceived social support level among the Vietnamese elderly might be one of the consequences of social modernization, which is currently spreading quickly in Vietnam; the younger generation tends to migrate to bigger cities and leave older persons on their own [37]. Moreover, Vietnamese elderly are exposed to less social interactions due to the limited social activities held by the local 
Table 2 Associations between participants' characteristics and FoF, unadjusted logistic analysis $(n=725)$

\begin{tabular}{|c|c|c|c|}
\hline & & \multicolumn{2}{|c|}{ Fear of falling } \\
\hline & & $\mathrm{OR}$ & $95 \% \mathrm{Cl}$ \\
\hline \multicolumn{4}{|c|}{ Socio-demographic characteristic } \\
\hline \multirow[t]{2}{*}{ Gender } & Male & 1 & \\
\hline & Female & $2.90^{* * *}$ & $(2.11-3.89)$ \\
\hline \multirow[t]{3}{*}{ Age (yr) } & $60-69$ & 1 & \\
\hline & $70-79$ & $2.05^{* * *}$ & $(1.43-2.94)$ \\
\hline & $\geq 80$ & $4.65^{* * *}$ & $(3.15-6.86)$ \\
\hline \multirow[t]{2}{*}{ Residential area } & Hue city & 1 & \\
\hline & Phu Vang District & 1.33 & $(0.98-1.80)$ \\
\hline \multirow[t]{2}{*}{ Marital status } & Married & 1 & \\
\hline & Single or formerly married & $2.33^{* * *}$ & $(1.67-3.24)$ \\
\hline \multirow[t]{3}{*}{ Education level } & College and higher & 1 & \\
\hline & Low education & 5.61 & $(2.78-11.32)$ \\
\hline & Primary to high school & 1.88 & $(0.96-3.66)$ \\
\hline \multirow[t]{2}{*}{ Living arrangement } & Living with others & 1 & \\
\hline & Alone & $2.35^{* *}$ & $(1.40-3.96)$ \\
\hline \multicolumn{4}{|l|}{ Physical functional status } \\
\hline \multirow[t]{2}{*}{ Experience of injury } & No & 1 & \\
\hline & Yes & $4.95^{* * *}$ & $(2.70-9.06)$ \\
\hline \multirow[t]{2}{*}{ History of fall } & No & 1 & \\
\hline & Yes & $5.75^{* * *}$ & $(2.97-11.12)$ \\
\hline \multirow[t]{2}{*}{ Arthritis } & No & 1 & \\
\hline & Yes & $1.79 * * *$ & $(1.31-2.44)$ \\
\hline \multirow[t]{2}{*}{ Hypertension } & No & 1 & \\
\hline & Yes & $1.49^{* *}$ & $(1.11-2.01)$ \\
\hline \multirow[t]{2}{*}{ Limitation of the IADL } & No & 1 & \\
\hline & Yes & $8.48^{* * *}$ & $(5.96-12.07)$ \\
\hline \multirow[t]{2}{*}{ Limitation of the BADL } & No & 1 & \\
\hline & Yes & $10.84^{* * *}$ & $(6.58-17.85)$ \\
\hline \multirow[t]{2}{*}{ Visual ability } & No difficulty & 1 & \\
\hline & Have difficulty & $3.09 * * *$ & $(2.27-4.21)$ \\
\hline \multirow[t]{2}{*}{ Walking ability } & No difficulty & 1 & \\
\hline & Have difficulty & $9.78^{* * *}$ & $(6.75-14.17)$ \\
\hline \multirow[t]{3}{*}{ Social support } & High & 1 & \\
\hline & Low & $2.04^{* *}$ & $(1.21-3.45)$ \\
\hline & Moderate & 0.92 & $(0.67-1.26)$ \\
\hline \multirow[t]{2}{*}{ Cognitive function } & Normal & 1 & \\
\hline & Impairment & $6.42^{* * *}$ & $(4.10-10.06)$ \\
\hline
\end{tabular}

OR Odds Ratio; $95 \% \mathrm{Cl}=95 \%$ Confidence interval

${ }^{*} p<0.05 ;{ }^{* *} p<0.01 ;{ }^{* * *} p<0.001$

authority as compared to other developed countries [6]. Elderly with lower levels of social support are more likely to be physically inactive [38], depressed [36, 39, 40], which are reported to be closely related to FoF [18,
41]. In addition, we found that the mean MMSE score of the participants with low-moderate perceived social support levels was 25.5 , which was significantly lower than that of those with a high perceived level of social 
Table 3 Associations between participants' characteristics and FoF by social support level, adjusted logistic analysis ( $n=725)$

\begin{tabular}{|c|c|c|c|}
\hline & & \multicolumn{2}{|c|}{ Fear of falling } \\
\hline & & $\begin{array}{l}\text { Model } 1 \\
\text { Low - moderate social support level } \\
(n=423)\end{array}$ & $\begin{array}{l}\text { Model } 2 \\
\text { High social support level } \\
(n=302)\end{array}$ \\
\hline & & $\mathrm{AOR}(95 \% \mathrm{Cl})^{1}$ & AOR $(95 \% \mathrm{Cl})$ \\
\hline \multirow[t]{2}{*}{ Gender } & Male & 1 & 1 \\
\hline & Female & $1.99(1.10-3.59)^{*}$ & $1.91(0.93-3.92)$ \\
\hline \multirow[t]{3}{*}{ Age $(y r)$} & $60-69$ & 1 & 1 \\
\hline & $70-79$ & $1.13(0.63-2.02)$ & $1.61(0.77-3.33)$ \\
\hline & $\geq 80$ & $1.55(0.77-3.10)$ & $1.79(0.73-4.40)$ \\
\hline \multirow[t]{2}{*}{ Marital status } & Married & 1 & 1 \\
\hline & Single or formerly married & $1.23(0.72-2.12)$ & $0.62(0.25-1.53)$ \\
\hline \multirow[t]{2}{*}{ History of fall } & No & 1 & 1 \\
\hline & Yes & $3.36(1.30-8.68)^{*}$ & $4.61(1.09-19.57)^{*}$ \\
\hline \multirow[t]{2}{*}{ Arthritis } & No & 1 & 1 \\
\hline & Yes & $1.36(0.80-2.33)$ & $0.82(0.41-1.62)$ \\
\hline \multirow[t]{2}{*}{ Hypertension } & No & 1 & 1 \\
\hline & Yes & $0.62(0.37-1.01)$ & $1.06(0.56-1.99)$ \\
\hline \multirow[t]{2}{*}{ Limitation of the IADL } & No & 1 & 1 \\
\hline & Yes & $2.40(1.31-4.39)^{* *}$ & $3.41(1.51-7.71)^{* *}$ \\
\hline \multirow[t]{2}{*}{ Limitation of the BADL } & No & 1 & 1 \\
\hline & Yes & $2.35(1.11-4.98)^{*}$ & $4.68(1.56-14.03)^{* *}$ \\
\hline \multirow[t]{2}{*}{ Visual ability } & No difficulty & 1 & 1 \\
\hline & Difficulty & $1.40(0.84-2.33)$ & $1.73(0.94-3.21)$ \\
\hline \multirow[t]{2}{*}{ Walking ability } & No difficulty & 1 & 1 \\
\hline & Difficulty & $2.58(1.37-4.86)^{* *}$ & $4.62(2.17-9.82)^{* * *}$ \\
\hline \multirow[t]{2}{*}{ Cognitive function } & Normal & 1 & 1 \\
\hline & Impairment $^{2}$ & $2.97(1.49-5.89)^{* *}$ & $1.04(0.38-2.82)$ \\
\hline Pseudo $R^{2}$ & & 0.31 & 0.36 \\
\hline
\end{tabular}

${ }^{1} A O R$ Adjusted odd ratio; $95 \% \mathrm{Cl}=95 \%$ Confidence interval

Adjusted for age, gender, marital status, history of fall, arthritis, hypertension, limitation of the IADL, limitation of the BADL, visual ability, walking ability and cognitive function

${ }^{2}$ Cognitive impairment was defined by a score lower than the cut-off score of 23

${ }^{*} p<0.05 ;{ }^{* *} p<0.01 ;{ }^{* * *} p<0.001$

support (26.6) (Additional file 2). This was also in line with a prior finding in an Asia setting of a positive relationship between better cognitive function and a higher social support level [16]. Accordingly, an ageing-friendly environment, such as the availability of wide sidewalks, a proper rainwater drainage system, and establishment of more social activities for the elderly in the community may represent some solutions to prevent FoF, especially in the elderly with limited social support and impairedcognition.

However, this association between cognitive decline and the FoF was no longer seen in participants with perceived high social support levels. Considering the close-knit community culture in Thua Thien Hue province, older adults with a high perceived level of social support are more likely to be surrounded by their families, neighbors and/or friends, which is beneficial in enhancing their wellbeing and physical health $[42,43]$, consequently maintaining their cognitive functions [16] and reducing the odds of FoF [1719]. Thus, it can be inferred that good social support is valuable for eliminating the FoF in the elderly, irrespective of whether they suffer from cognitive impairment or not.

\section{Strengths and limitations}

To the best of our knowledge, the current study is the first study conducted in Vietnam to assess the 
association between FoF and cognitive function in the elderly according to their social support status. The study was conducted on a large representative sample of Vietnamese elderly, with a high response rate and an appropriate sampling method. FoF, perceived social support and cognitive function were measured using standardized and validated scales. However, being a cross-sectional study, no causal inference could be drawn and the results should therefore be interpreted with caution. A further longitudinal study is needed to investigate the two-way associations between the FoF and other factors. In addition, it is possible that the number of previous falls was underreported, because there was no direct question addressing this, and a history of fall was explored based on the types of bodily injury experienced by the participants during the last 12 months. However, we still found a significant association between a history of fall and a high FoF.

Given the fact that the coefficient of determination Pseudo $R^{2}$ indicated that the independent variables explained 31 and 36\% of variance of FoF in model 1 and model 2 respectively, results from this study should be interpreted with caution. However, the Goodness of Fit test suggested that these models were a good fit to the data as $p=0.6(>0.05$, model 1$)$ and $p=0.7$ ( $>0.05$, model 2). Future studies are encouraged to consider other factors such as living conditions, psychology or physiological function in the research components.

\section{Implications}

Our results highlight the important implications of the FoF for the vulnerable elderly living in the community. Although cognitive or functional impairment in older adults is inevitable with advancing age, factors such as the social support status are modifiable. Despite the fact that from a cultural perspective, Vietnamese elderly are respected and well supported, more than a half of the elderly (423/725) in this study perceived low or moderate level of social support in this study. With the recognition of this emerging issue, identification of isolated elderly in the community might be one of effective approaches for addressing individuals with a high risk of FoF. This could be done in practice by keeping close communication with local organizations such as Associations of the Elderly at community level, community health centers or provincial People's Committees. Therefore, involvement of caregivers and stakeholders are important in improving the social support status of the elderly, by developing public programs focusing on social relationships and interactions, along with strengthening of the infrastructure in community to encourage more participation from the elderly.

\section{Conclusions}

In summary, our study confirmed a high prevalence of a high FoF in an aging Vietnamese, and a number of factors associated with a FoF were identified. Our findings also indicated that cognitive impairment exerted differential effects on the likelihood of a high FoF in the elderly depending on the perceived social support levels. These findings are expected to be useful not only to screen for people who may benefit from fall-related programs, but for health care providers to devise well-targeted strategies towards prevention of falls and provide satisfactory interventions for the elderly residing in the community.

\section{Supplementary information}

Supplementary information accompanies this paper at https://doi.org/10. 1186/s12877-020-01533-8.

Additional file 1. Fully adjusted model to determine the associations between the participants' characteristics and the fear of falling.

Additional file 2. Mean MMSE score of participants of low-moderate social support level and high social support level.

\section{Abbreviations}

$\mathrm{Cl}$ : Confidence interval; OR: Odds ratio; AOR: Adjusted odd ratio; FoF: Fear of falling; FES-I: Fall Efficacy Scale-International; MMSE: Mini-Mental State

Examination; IADL: Instrumental Activities of Daily Living Scale; BADL: Barthel Activities of Daily Living index; MSPSS: Multidimensional Scale of Perceived Social Support

\section{Acknowledgments}

We gratefully acknowledge College of Medicine and Pharmacy, Hue University (Hue CMP) and WHO Centre for Health Development for their support of this study. We deeply thank all local organizations, provincial Department of Health, participants in Thua Thien Hue province and especially Dr. Vo Nu Hong Duc and staffs from Institute for Community Health Research (ICHR) and Faculty of Public health of Hue CMP for data collection in fieldwork.

Authors' contributions

THMV and KN contributed to the design of the study, conceptualization, statistical analysis, interpretation data and drafted the manuscript. KN and TW coordinated the study design and data collection. THMV, KN, KS, HTLN and TW critically revised the draft manuscript. All authors have read and approved the final manuscript.

\section{Funding}

This study was supported by the grant of ICHR and the World Health Organization Centre for Health Development (WHO Kobe Centre - WKC: K18017).

\section{Availability of data and materials}

Datasets used for this study are not publicly shared due to participants confidentiality, but are accessible from Institute for Community Health Research, College of Medicine and Pharmacy, Hue University on reasonable request for research.

\section{Ethics approval and consent to participate}

This study was conducted according to the approval of the Institutional Ethics Committee of Hue University of Medicine and Pharmacy (No. H2018/ 14812 May 2018). Written informed consent was obtained from all participated subjects. When interviewers who received training on mental health evaluation observed a need of getting consent by the guardian of the subjects, the guardian provided consent on behalf of the subjects. The participants understood that the survey would be done anonymously and the data would be used for research purposes only. 


\section{Consent for publication}

Not applicable.

\section{Competing interests}

The authors declare that they have no competing interests.

\section{Author details}

'Department of Global Health Entrepreneurship, Division of Public Health, Graduate School of Medical and Dental Sciences, Tokyo Medical and Dental University, Yushima 1-5-45, Bunkyo-ku, Tokyo 113-8519, Japan. ${ }^{2}$ Faculty of Public Health, College of Medicine and Pharmacy, Hue University, Hue, Vietnam. ${ }^{3}$ The Institute for Community Health Research, College of Medicine and Pharmacy, Hue University, Hue, Vietnam.

Received: 23 July 2019 Accepted: 23 March 2020

Published online: 16 April 2020

\section{References}

1. World Health Organization. WHO Global Report on Falls Prevention in Older Age. Geneva: World Health Organization; 2007

2. Tinetti ME, Powell L. Fear of falling and low self-efficacy: a case of dependence in elderly persons. J Gerontol. 1993:48:35-8.

3. Scheffer AC, Schuurmans MJ, Van Dijk N, Van Der Hooft T, De Rooij SE. Fear of falling: measurement strategy, prevalence, risk factors and consequences among older persons. Age Ageing. 2008;37:19-24. https://doi.org/10.1093/ ageing/afm 169 .

4. Austin N, Devine A, Dick I, Prince R, Bruce D. Fear of falling in older women: a longitudinal study of incidence, persistence, and predictors. J Am Geriatr Soc. 2007;55:1598-603. https://doi.org/10.1111/j.1532-5415.2007.01317.x.

5. Uemura K, Shimada H, Makizako H, Doi T, Tsutsumimoto K, Lee S, et al. Effects of mild cognitive impairment on the development of fear of falling in older adults: A prospective cohort study. J Am Med Dir Assoc. 2015;16: 1104.e9-1104.e13. doi:https://doi.org/10.1016/j.jamda.2015.09.014.

6. Hoang OTT, Jullamate P, Piphatvanitcha N, Rosenberg E. Factors related to fear of falling among community-dwelling older adults. J Clin Nurs. 2017;26: 68-76. https://doi.org/10.1111/jocn.13337.

7. Van Der Meulen E, Zijlstra GAR, Ambergen T, Kempen GIJM. Effect of fallrelated concerns on physical, mental, and social function in communitydwelling older adults: a prospective cohort study. J Am Geriatr Soc. 2014;62: 2333-8. https://doi.org/10.1111/jgs.13083.

8. Park J-I, Yang J-C, Chung S. Risk factors associated with the fear of falling in community-living elderly people in Korea: role of psychological factors. Psychiatry Investig. 2017;14:894-9. https://doi.org/10.4306/pi.2017.14.6.894.

9. Hajek A, Bock J-O, König H-H. Psychological correlates of fear of falling: findings from the German aging survey. Geriatr Gerontol Int. 2018;18:396406. https://doi.org/10.1111/ggi.13190.

10. Pinto JM, Neri AL. Factors related to low social participation in older adults: findings from the Fibra study, Brazil. Cad Saúde Coletiva. 2017:25:286-93.

11. Friedman SM, Munoz B, West SK, Rubin GS, Fried LP. Falls and fear of falling: which comes first? A longitudinal prediction model suggests strategies for primary and secondary prevention. J Am Geriatr Soc. 2002;50:1329-35. https://doi.org/10.1046/j.1532-5415.2002.50352.x.

12. Peeters $G$, Leahy $S$, Kennelly $S$, Kenny RA. Is fear of falling associated with decline in global cognitive functioning in older adults: Findings from the Irish longitudinal study on ageing. J Am Med Dir Assoc. 2018;19:248-254.e3. https://doi.org/10.1016/j.jamda.2017.09.012.

13. Shirooka H, Nishiguchi S, Fukutani N, Tashiro Y, Nozaki Y, Hirata H, et al. Cognitive impairment is associated with the absence of fear of falling in community-dwelling frail older adults. Geriatr Gerontol Int. 2017:17:232-8. https://doi.org/10.1111/ggi.12702.

14. Bich NN, Thi N, Dung T, Vu T, Quy LT, Tuan NA, et al. Dementia and associated factors among the elderly in Vietnam: a cross-sectional study. Int J Ment Heal Syst. 2019;13:57. https://doi.org/10.1186/s13033-019-0314-7.

15. Dupertuis $L L$, Aldwin CM, BossÉ R. Does the source of support matter for different health outcomes? J Aging Health. 2001;13:494-510. https://doi.org/ $10.1177 / 089826430101300403$.

16. Yeh S-CJ, Liu Y-Y. Influence of social support on cognitive function in the elderly. BMC Health Serv Res. 2003;3:9. https:/doi.org/10.1186/1472-6963-3-9.

17. Kumar A, Carpenter H, Morris R, lliffe S, Kendrick D. Which factors are associated with fear of falling in community-dwelling older people? Age Ageing. 2014;43:76-84. https://doi.org/10.1093/ageing/aft154
18. Lee $\mathrm{S}$, Oh E, Hong GRS. Comparison of factors associated with fear of falling between older adults with and without a fall history. Int J Environ Res Public Health. 2018;15. https://doi.org/10.3390/ijerph15050982.

19. Dierking L, Markides K, Al Snih S, Kristen PM. Fear of falling in older Mexican Americans: a longitudinal study of incidence and predictive factors. J Am Geriatr Soc. 2016;64:2560-5. https://doi.org/10.1111/jgs.14496.

20. United Nations Population Fund: Ageing in the Twenty-First Century: A Celebration and A Challenge. (2012) www.unfpa.org. Accessed 2 Jun 2019.

21. United Nations Population Fund Viet Nam: Factsheet Rapid population ageing in Viet Nam: Challenges and opportunities. (2016) http://vietnam. unfpa.org. Accessed 10 May 2019

22. General Statistics Office Of Vietnam. https://www.gso.gov.vn/default_en. aspx?tabid=774. Accessed 11 Jun 2019.

23. Official Gazette Ordinance on elderly people (No.23/2000/PL-UBTVQH10). http://ilo.org/dyn/natlex/natlex4.detail?p_lang=en\&p_isn=57288\&p_ country=VNM\&p_count=532 Accessed 4 Dec 2019.

24. Vietnam Woman Union (2012). Viet nam Aging Survey (vnas), 2011: key findings. 2012

25. Delbaere K, Close JCT, Mikolaizak AS, Sachdev PS, Brodaty H, Lord SR. The falls efficacy scale international (FES-I). A comprehensive longitudinal validation study. Age Ageing. 2010;39:210-6. https://doi.org/10.1093/ageing/afp225.

26. Zimet GD, Dahlem NW, Zimet SG, Farley GK. The multidimensional scale of perceived social support. J Pers Assess. 1988;52:30-41. https://doi.org/10. 1207/s15327752jpa5201_2.

27. Mcdowell I. Measuring Health. A guide to rating scales and questionnaires. In: 8. Mental Status Testing. 3rd ed; 2006. p. 430.

28. Wade DT, Collin C. The Barthel ADL index: a standard measure of physical disability? Int Disabil Stud. 1988;10:64-7.

29. Lawton MP, Brody EM. Assessment of Older People: Self-Maintaining and Instrumental Activities of Daily Living. Gerontologist. 1969;9(3 Part 1):179-86. https://doi.org/10.1093/geront/9.3_Part_1.179.

30. Boyd R, Stevens JA. Falls and fear of falling falls and fear of falling: burden, beliefs and behaviours; 2009. https://doi.org/10.1093/ageing/afp053.

31. Tomita Y, Arima K, Tsujimoto R, Kawashiri S-Y, Nishimura T, Mizukami S, et al. Prevalence of fear of falling and associated factors among Japanese community-dwelling older adults; 2018. https://doi.org/10.1097/MD 0000000000009721.

32. Mortazavi H, Tabatabaeichehr M, Taherpour M, Masoumi M. Relationship between home safety andprevalence of falls and fear of falling among elderly people: a cross-sectional study. Mater Socio Medica. 2018:30:103. https://doi.org/10.5455/msm.2018.30.103-107.

33. Noi $\mathrm{H}$. Institute of Meteorological, hydrological and environment Ministry of Foreign affairs of the Netherlands the Netherlands climate assistance program PROJECT climate change impacts in Huong River basin and adaptation in its Coastal District Phu Vang, Thua Thien hue province final report. 2008. Accessed 29 May 2019.

34. Root-Bernstein R. Brain aging: models, methods, and mechanisms. Jama. 2007;298:2796

35. Malini FM, Lourenço RA, Lopes CS. Prevalence of fear of falling in older adults, and its associations with clinical, functional and psychosocial factors: the frailty in Brazilian older people-Rio de Janeiro study. Geriatr Gerontol Int. 2016;16:336-44. https://doi.org/10.1111/ggi.12477.

36. Jane AP, Leslie A, Puneet D, Justin D, Kira C, Leonard GT. Fear of falling and its relationship with anxiety, depression, and activity engagement among community-dwelling older adults. Am J Occup Ther. 2012:169. https://doi. org/10.5014/ajot.2012.002535

37. Teramoto $M_{1}$ Chien ND, Iwai $M_{1}$ Cuong BT. The Vietnamese family during the period of promoting industrialization, modernization and international integration. Chiba: IDE-JETRO; 2017.

38. Ståhl T, Rütten A, Nutbeam D, Bauman A, Kannas L, Abel T, et al. The importance of the social environment for physically active lifestyle--results from an international study. Soc Sci Med. 2001;52:1-10. https://doi.org/10. 1016/s0277-9536(00)00116-7

39. Van Orden KA, Li Y, Podgorski CA, Conwell Y. The association between higher social support and lower depressive symptoms among aging services clients is attenuated at higher levels of functional impairment. Int $J$ Geriatr Psychiatry. 2015;30:1085-92. https://doi.org/10.1002/gps.4266.

40. Kurlowicz LH. Social factors and depression in late life. Arch Psychiatr Nurs. 1993;7:30-6. https://doi.org/10.1016/0883-9417(93)90020-w.

41. Mishra N, Kumar Mishra A, Bidija M. A study on correlation between depression, fear of fall and quality of life in elderly individuals. Int J Res Med 
Sci Mishra N al Int J Res Med Sci. 2017;5:1456-60. https://doi.org/10.18203/ 2320-6012.jijms20171245.

42. Krause N. Life stress, social support, and self-esteem in an elderly population. Psychol Aging. 1987;2:349-56. https://doi.org/10.1037//08827974.2.4.349

43. Reblin M, Uchino BN. Social and emotional support and its implication for health. Curr Opin Psychiatry. 2008;21:201-5. https://doi.org/10.1097/YCO. 0b013e3282f3ad89.

\section{Publisher's Note}

Springer Nature remains neutral with regard to jurisdictional claims in published maps and institutional affiliations.

Ready to submit your research? Choose BMC and benefit from:

- fast, convenient online submission

- thorough peer review by experienced researchers in your field

- rapid publication on acceptance

- support for research data, including large and complex data types

- gold Open Access which fosters wider collaboration and increased citations

- maximum visibility for your research: over $100 \mathrm{M}$ website views per year

At $\mathrm{BMC}$, research is always in progress. 